\title{
Temperature Dependent Viscosity of a Third Order Thin Film Fluid Layer on a Lubricating Vertical Belt
}

\author{
T. Gul, ${ }^{1}$ S. Islam, ${ }^{1}$ R. A. Shah, ${ }^{2}$ I. Khan, ${ }^{3}$ and L. C. C. Dennis ${ }^{4}$ \\ ${ }^{1}$ Department of Mathematics, Abdul Wali Khan University Mardan, Khyber Pakhtunkhwa, Pakistan \\ ${ }^{2}$ Department of Mathematics, UET Peshawar, Khyber Pakhtunkhwa, Pakistan \\ ${ }^{3}$ College of Engineering, Majmaah University, Saudi Arabia \\ ${ }^{4}$ Department of Fundamental and Applied Sciences, Universiti Teknologi PETRONAS, 31750 Perak, Malaysia
}

Correspondence should be addressed to L. C. C. Dennis; dennis.ling@petronas.com.my

Received 23 July 2014; Revised 28 September 2014; Accepted 30 September 2014

Academic Editor: Yasir Khan

Copyright (C) 2015 T. Gul et al. This is an open access article distributed under the Creative Commons Attribution License, which permits unrestricted use, distribution, and reproduction in any medium, provided the original work is properly cited.

This paper aims to study the influence of heat transfer on thin film flow of a reactive third order fluid with variable viscosity and slip boundary condition. The problem is formulated in the form of coupled nonlinear equations governing the flow together with appropriate boundary conditions. Approximate analytical solutions for velocity and temperature are obtained using Adomian Decomposition Method (ADM). Such solutions are also obtained by using Optimal Homotopy Asymptotic Method (OHAM) and are compared with ADM solutions. Both of these solutions are found identical as shown in graphs and tables. The graphical results for embedded flow parameters are also shown.

\section{Introduction}

Thin film fluid flows exist in various aspects of daily life. In engineering, we see their usage in condensers, distillation units, and heat exchangers. In geophysical events, we see thin fluid films in the forms of drilling mud, heat pipes, and debris flow. In biological sciences, we can see thin fluid films coating the airways in the lungs and thin tear films covering the eye. These are a few examples of common use of thin fluid films. All these occurrences can be modeled using mathematical principles. The material properties such as viscosity and density change accordingly when a fluid is subjected to a temperature change. This phenomenon mostly occurs in heat exchangers, chemical reactors, or processes where components are cooled.

Properties of isothermal flows (viscosity at constant temperature) are important in many situations. There have also been many studies done on variety of nonisothermal (temperature dependent viscosity) flows of fluids; particularly, Goussis and Kelly [1,2] and Hwang and Weng [3] investigated the stability of a fluid film with variable viscosity flowing down a heated plan, while Reisfeld and Bankoff [4] and $\mathrm{Wu}$ and Hwang [5] independently considered the progression and final substrate of a fluid film with variable viscosity on a heated horizontal substrate subjected to surface tension and van der Waals forces. Sansom et al. [6] considered the scattering of a thin film flow with temperature dependent viscosity on a horizontal substrate for different viscosity models for both heated and cooled substrate without internal heating within the film and for a substrate at the ambient temperature with constant internal heating within the film.

Many researchers have contributed relevant work in this field. Amongst them, Khaled et al. [7] studied heat transfer inside thin film flow with variable pressure whereas Nadeem and Awais [8] investigated the thin film unsteady flow with variable viscosity. The free micropolar convection for the case of a symmetric boundary conditions or asymmetric heating was investigated by Chamkha et al. [9], later on proceeded by Saleh et al. [10]. Few other relevant studies may be found in $[11,12]$ and the references therein. One of the well-known models amongst non-Newtonian fluids for thin film is a third grade fluid which has its constitutive equations based on 
strong theoretical foundations, where the relation between stress and strain is nonlinear. Therefore, in the present work we have chosen third grade fluid to study its thin film flow over a vertical belt.

On the other hand, several numerical and approximate methods are used by many authors to study real world problems, appearing in mathematics, fluid mechanics, and engineering sciences. Few of these methods include Kellerbox [13], shooting [14], Homotopy Perturbation Method (HPM) [15], Homotopy Analysis Method (HAM), and Optimal Homotopy Asymptotic Method (OHAM) [16, 17]. Applications of OHAM for solving nonlinear equations arising in heat transfer have been investigated by Marinca and Herisanu [18]. Marinca et al. [19] analysed steady flow of a fourth grade fluid past a porous plate using OHAM. Micropolar flow in a porous channel with high mass transfer has been investigated by Joneidi [20]. These methods deal with the nonlinear problems effectively. The work under various configurations on the thin film flows has been discussed by Siddiqui et al. [21]. In [22], Siddiqui et al. examined the thin film flows of Sisko and Oldroyd- 6 constant fluids on a moving belt. Using the same idea, Gul et al. $[23,24]$ investigated MHD thin film flow of a third grade fluid for lifting and drainage problems. Constant and variable viscosity fluid has been used in all these studies. In [24] they studied variable viscosity with noslip boundary conditions. However, in the present problem we have chosen Reynolds model (exponential expression) which is based on variable viscosity in the presence of slip boundary conditions. More exactly, we have shown the effect of variable viscosity with heat transfer in a thin film fluid flow such as silicate melts and polymers past a lubricating belt. In these fluids, viscous friction generates a local increase in temperature near the belt with a resultant viscosity decrease and frequent rise of the flow velocity. This velocity increase may produce an additional growth of the local temperature discussed by Costa et al. [25]. Analytical solution for MHD flow in a third grade fluid with variable viscosity has been discussed by Ellahi and Riaz [26]. Approximate analytical solution for flow of a third grade fluid through a parallel plate channel filled with a porous medium has been investigated by Aksoy et al. [27].

Based on the above motivation, the present paper aims to study the effect of heat on viscosity into a thin film flow of a third grade fluid over a vertical belt with slip boundary conditions using ADM and OHAM. In 1992, Adomian [28, 29] introduced the $\mathrm{ADM}$ for the approximate solutions for linear and nonlinear problems. Wazwaz [30, 31] used ADM for reliable treatment of Bratu-type and Emden-Fowler equations. Alam et al. investigated the thin film flow of Johnson-Segalman fluids for lifting and drainage problems [32].

\section{Basic Equations}

Continuity, momentum, and energy equations of an incompressible isothermal third grade fluid are

$$
\boldsymbol{\nabla} \cdot \mathbf{v}=\mathbf{0},
$$

$$
\begin{aligned}
\rho \frac{D \mathbf{v}}{D t} & =\nabla \cdot \mathbf{T}+\rho \mathbf{g}, \\
\rho c_{p} \frac{D \Theta}{D t} & =\kappa \nabla^{2} \Theta+\operatorname{tr}(\mathbf{T} \cdot \mathbf{L}),
\end{aligned}
$$

where $\mathbf{L}=\nabla \mathbf{v}$ and $D / D t=\partial / \partial t+(\mathbf{v} \cdot \boldsymbol{\nabla})$ denotes material time derivative.

Cauchy stress tensor $\mathbf{T}$ is given by

$$
\mathbf{T}=-p \mathbf{I}+\mathbf{S}
$$

where $-p \mathbf{I}$ denotes spherical stress and shear stress $\mathbf{S}$ is defined as

$$
\begin{aligned}
\mathbf{S}= & \mu \mathbf{A}_{1}+\alpha_{1} \mathbf{A}_{2}+\alpha_{2} \mathbf{A}_{1}^{2}+\beta_{1} \mathbf{A}_{3}+\beta_{2}\left(\mathbf{A}_{1} \mathbf{A}_{2}+\mathbf{A}_{2} \mathbf{A}_{1}\right) \\
& +\beta_{3}\left(\operatorname{tr} \mathbf{A}_{2}^{2}\right) \mathbf{A}_{1} .
\end{aligned}
$$

Here $\mathbf{A}_{1}, \mathbf{A}_{2}$, and $\mathbf{A}_{3}$ are the kinematical tensors given by

$$
\begin{aligned}
& \mathbf{A}_{0}=\mathbf{I}, \\
& \mathbf{A}_{1}=(\nabla \mathbf{v})+(\nabla \mathbf{v})^{T}, \\
& \mathbf{A}_{n}=\frac{D \mathbf{A}_{n-1}}{D t}+\mathbf{A}_{n-1}(\nabla \mathbf{v})+(\nabla \mathbf{v})^{T} \mathbf{A}_{n-1}, \quad n \geq 2 .
\end{aligned}
$$

\section{Formulation of the Lift Problem}

Consider a wide flat belt moves vertically upward at constant speed $V$ through a large bath of a third grade liquid. The belt carries with it a layer of liquid of constant thickness $\delta$. Cartesian coordinate system is chosen for analysis in which the $y$-axis is taken parallel to the belt and $x$-axis is perpendicular to the belt. Assume that the flow is steady and laminar after a small distance above the liquid surface layer while external pressure is atmospheric everywhere. The geometry of the problems is shown in Figures 1(a) and 1(b).

Velocity and temperature fields are

$$
\begin{aligned}
& \mathbf{v}=(0, v(x), 0), \\
& \Theta=\Theta(x) .
\end{aligned}
$$

Modeled slip boundary conditions are

$$
\begin{aligned}
\mathbf{v} & =V-\gamma T_{x y}, \quad \Theta=\Theta_{0}, \quad \text { at } x=0, \\
\frac{d \mathbf{v}}{d x} & =0, \quad \Theta=\Theta_{1}, \quad \text { at } x=\delta .
\end{aligned}
$$

Inserting the velocity field from (7) in continuity equation (1) and in Cauchy stress equation (4), the continuity equation (1) satisfies identically while (4) gives the components of stress tensor as

$$
\begin{aligned}
& T_{y y}=-P+\left(2 \alpha_{1}+\alpha_{2}\right)\left(\frac{d \mathbf{v}}{d x}\right)^{2}, \\
& T_{x y}=\mu \frac{d \mathbf{v}}{d x}+2\left(\beta_{2}+\beta_{3}\right)\left(\frac{d \mathbf{v}}{d x}\right)^{3},
\end{aligned}
$$




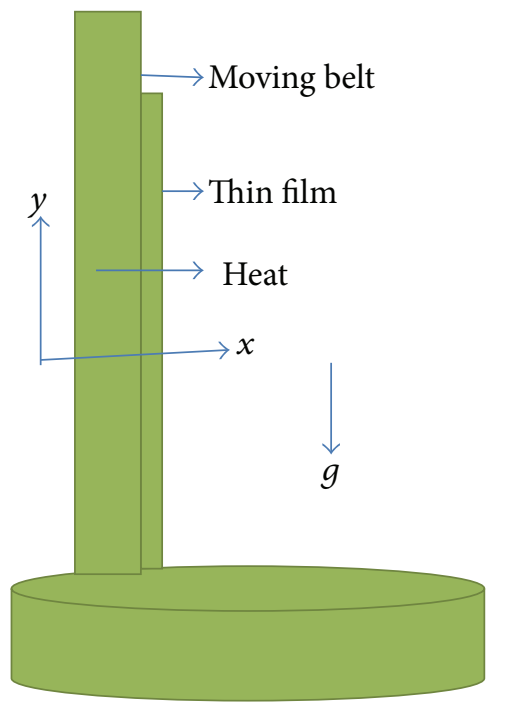

(a)

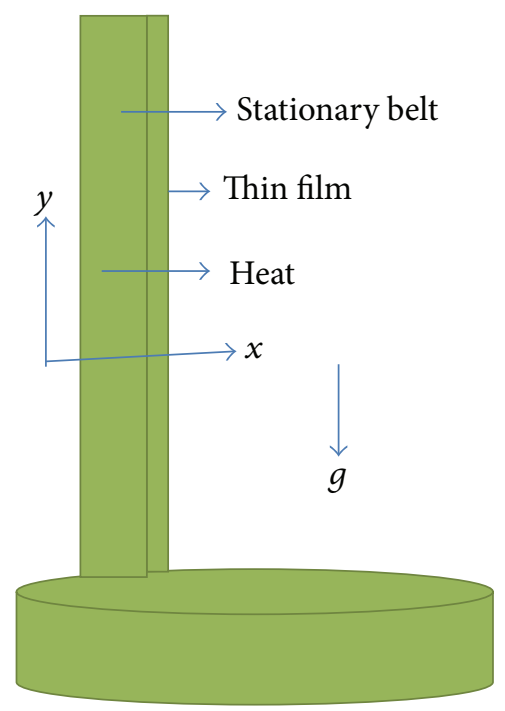

(b)

Figure 1: (a) Geometry of lift problem. (b) Geometry of drainage problem.

$$
\begin{aligned}
& T_{x x}=-P+\alpha_{2}\left(\frac{d \mathbf{v}}{d x}\right), \\
& T_{z z}=-P, \\
& T_{x z}=T_{y z}=0 .
\end{aligned}
$$

Inserting (9) in (2) and (3), the momentum and energy equations reduce to

$$
\begin{aligned}
0= & \mu \frac{d^{2} \mathbf{v}}{d x^{2}}+\frac{d v}{d x} \frac{d \mu}{d x}+6\left(\beta_{2}+\beta_{3}\right)\left(\frac{d v}{d x}\right)^{2}\left(\frac{d^{2} v}{d x^{2}}\right) \\
& -\rho g \\
0= & \kappa \frac{d^{2} \boldsymbol{\Theta}}{d x^{2}}+\mu\left(\frac{d \mathbf{v}}{d x}\right)^{2}+2\left(\beta_{2}+\beta_{3}\right)\left(\frac{d \mathbf{v}}{d x}\right)^{4} .
\end{aligned}
$$

In addition, we introduce the dimensionless parameters

$$
\begin{aligned}
\widetilde{v} & =\frac{\mathbf{v}}{V}, \\
\widetilde{x} & =\frac{x}{\delta}, \\
\widetilde{\Theta} & =\frac{\Theta-\Theta_{0}}{\Theta_{1}-\Theta_{0}}, \\
\widetilde{\mu} & =\frac{\mu}{\mu_{0}}, \\
\widetilde{\gamma} & =\frac{\gamma}{\gamma_{0}}, \\
B_{r} & =\frac{\mu_{0} V^{2}}{k\left(\Theta_{1}-\Theta_{0}\right)},
\end{aligned}
$$

$$
\begin{aligned}
& S_{t}=\frac{\delta^{2} \rho g}{\mu_{0} V}, \\
& \beta=\frac{\left(\beta_{2}+\beta_{3}\right) V^{2}}{\mu_{0} \delta^{2}},
\end{aligned}
$$$$
\Lambda=\gamma \mu_{0} .
$$

For Reynold's model, the dimensionless viscosity is

$$
\mu=\exp (-M \Theta)
$$

By making use of Taylor series expansion, one may represent viscosity and its derivative as

$$
\begin{aligned}
& \mu \cong 1-M \Theta, \\
& \frac{d \mu}{d x} \cong-M \frac{d \Theta}{d x} .
\end{aligned}
$$

Inserting dimensionless variables from (11) in modeled boundary conditions (8) and in momentum as well as in energy equations (10) and dropping out the bar notations, we obtain

$$
\begin{gathered}
\frac{d^{2} v}{d x^{2}}-M\left(\frac{d v}{d x} \frac{d \Theta}{d x}+\Theta(x) \frac{d^{2} v}{d x^{2}}\right) \\
+6 \beta\left(\frac{d v}{d x}\right)^{2}\left(\frac{d^{2} v}{d x^{2}}\right)-S_{t}=0 \\
\frac{d^{2} \Theta}{d x^{2}}+B_{r}\left(\left(\frac{d v}{d x}\right)^{2}-M \Theta\left(\frac{d v}{d x}\right)^{2}+2 \beta\left(\frac{d v}{d x}\right)^{4}\right)=0 .
\end{gathered}
$$


According to Gul et al. [24] the boundary conditions for zero component solution are

$$
\begin{gathered}
v_{n}=1-\Lambda\left(\frac{d v_{n}}{d x}-M \Theta \frac{d v_{n}}{d x}+2 \beta\left(\frac{d v_{n}}{d x}\right)^{3}\right), \\
\Theta_{n}=0, \quad \text { at } x=0, \\
\frac{d v_{n}}{d x}=0, \quad \Theta_{n}=1, \quad \text { at } x=1, \text { when } n=0 .
\end{gathered}
$$

Similarly the boundary conditions for first, second, and third components solutions are

$$
\begin{gathered}
v_{n}=-\Lambda\left(\frac{d v_{n}}{d x}-M \Theta \frac{d v_{n}}{d x}+2 \beta\left(\frac{d v_{n}}{d x}\right)^{3}\right), \\
\Theta_{n}=0, \quad \text { at } x=0, \\
\frac{d v_{n}}{d x}=0, \quad \Theta_{n}=0, \quad \text { at } x=1, \text { when } n=1,2,3 \ldots
\end{gathered}
$$

\section{Solution of Lifting Problem}

4.1. The ADM Solution. The inverse operator $L^{-1}=\iint d v^{\prime}$ of the Adomian Decomposition Method is used in the second order coupled equations (14) and (15):

$$
\begin{aligned}
v= & f_{1}-6 \beta L^{-1}\left[\left(\frac{d v}{d x}\right)^{2} \frac{d^{2} v}{d^{2} x}\right] \\
& +M\left[\frac{d v}{d x} \frac{d \Theta}{d x}+\Theta \frac{d^{2} v}{d x^{2}}\right], \\
\Theta= & f_{2}-B_{r} L^{-1}\left(\frac{d v}{d x}\right)^{2}+B_{r} M L^{-1} \Theta\left(\frac{d v}{d x}\right)^{2} \\
& -2 B_{r} \beta L^{-1}\left(\frac{d v}{d x}\right)^{4},
\end{aligned}
$$

where $f_{1}, f_{2}$ are the terms, which we get by double integrating source terms $S_{t}, 0$ and using the boundary (initial) conditions. As ADM is a series solution method, according to Aksoy et al. [27], the solutions $\Theta$ and the nonlinear terms $N_{1} v, N_{2} v$, $N_{3} v, N_{4} \Theta, N_{5} \Theta$, and $N_{6} \Theta$ can be expressed, respectively, in the following series:

$$
\begin{aligned}
v & =\sum_{n=0}^{\infty} v_{n}, \\
\Theta & =\sum_{n=0}^{\infty} \Theta_{n}, \\
N_{1} v & =\sum_{n=0}^{\infty} \overbrace{A_{n}}=\left(\frac{d v}{d x}\right)^{2}\left(\frac{d^{2} v}{d x^{2}}\right),
\end{aligned}
$$

$$
\begin{aligned}
& N_{2} v=\sum_{n=0}^{\infty}{\widetilde{B_{n}}}_{n}=\left(\frac{d v}{d x}\right)\left(\frac{d \Theta}{d x}\right), \\
& N_{3} v=\sum_{n=0}^{\infty} \overbrace{n}=\Theta\left(\frac{d^{2} v}{d x^{2}}\right), \\
& N_{4} \Theta=\sum_{n=0}^{\infty} \overbrace{D_{n}}=\left(\frac{d v}{d x}\right)^{2}, \\
& N_{5} \Theta=\sum_{n=0}^{\infty} \overbrace{E_{n}}=\Theta\left(\frac{d v}{d x}\right)^{2}, \\
& N_{6} \Theta=\sum_{n=0}^{\infty} \overbrace{F_{n}}=\left(\frac{d v}{d x}\right)^{4},
\end{aligned}
$$

where $\overbrace{A_{n}}, \overbrace{B_{n}}, \overbrace{C_{n}}, \overbrace{D_{n}}, \overbrace{E_{n}}$, and $\overbrace{F_{n}}$ are called the Adomian polynomials. For every nonlinear term these polynomials are obtained from the following formula:

$$
\begin{aligned}
& \widetilde{A}_{0}=f_{1}\left(v_{0}\right), \\
& D_{0}=f_{2}\left(\Theta_{0}\right), \\
& \widetilde{A}_{i}=\overbrace{B}=\overbrace{i}=\sum_{\lambda=1}^{i} C(\lambda, n) f_{1}{ }^{(\lambda)}\left(v_{0}\right), \\
& \overbrace{D_{i}}=\overbrace{E_{i}}=\overbrace{F_{i}}=\sum_{\lambda=1}^{i} C(\lambda, n) f_{2}{ }^{(\lambda)}\left(\Theta_{0}\right) .
\end{aligned}
$$

Here $f_{1}(v)$ and $f_{2}(\Theta)$ are the nonlinear functions and $f_{1}{ }^{(\lambda)}$, $f_{2}{ }^{(\lambda)}$ are the $\lambda$ th derivative of $f_{1}(v)$ and $f_{2}(\Theta)$ evaluated at $v=v_{0}$ and $\Theta=\Theta_{0}$. The $(\lambda, n)$ is a well-situated representation of the series coefficients and is formed by forming products or sum of the products of $\lambda$ components of $v$ whose subscripts add up to $i$, divided by the factorial of the number of repeated subscripts [26]. The convergence of this method has been discussed in [28-30].

The series solutions of (20) are as follows:

$$
\begin{aligned}
\sum_{n=0}^{\infty} v_{n}= & f_{1}-6 \beta L^{-1}\left[\sum_{n=0}^{\infty} \widetilde{A}_{n}\right]+M L^{-1}[\sum_{n=0}^{\infty} \overbrace{B}] \\
& +M L^{-1}[\sum_{n=0}^{\infty} \overbrace{n}] \\
\sum_{n=0}^{\infty} \Theta_{n}= & f_{2}-B_{r} L^{-1}[\sum_{n=0}^{\infty} \overbrace{D_{n}}] \\
& +B_{r} M L^{-1}[\sum_{n=0}^{\infty} \overbrace{E_{n}}] \\
& -2 B_{r} \beta L^{-1}[\sum_{n=0}^{\infty} \overbrace{F_{n}}] .
\end{aligned}
$$


The first few Adomian polynomials are derived in (24) and (27) when $n \geq 0$ :

$$
\begin{aligned}
& \overbrace{A_{0}}=\left(\frac{d v_{0}}{d x}\right)^{2} \frac{d^{2} v_{0}}{d x^{2}}, \\
& \overbrace{B_{0}}=\frac{d v_{0}}{d x} \frac{d \Theta_{0}}{d x}, \\
& \widetilde{C}_{0}=\Theta_{0}(x) \frac{d^{2} v_{0}}{d x^{2}}, \\
& \overbrace{D_{0}}=\left(\frac{d v_{0}}{d x}\right)^{2} \text {, } \\
& \widetilde{E}_{0}=\Theta_{0}(x)\left(\frac{d v_{0}}{d x}\right)^{2} \text {, } \\
& \widetilde{F}_{0}=\left(\frac{d v_{0}}{d x}\right)^{4}, \\
& \overbrace{A_{1}}=\left(\frac{d v_{0}}{d x}\right)^{2} \frac{d^{2} v_{1}}{d x^{2}}+2 \frac{d v_{0}}{d x} \frac{d v}{d x}, \\
& \overbrace{B}=\frac{d v_{1}}{d x} \frac{d \Theta_{0}}{d x}+\frac{d v_{0}}{d x} \frac{d \Theta_{1}}{d x}, \\
& \overbrace{C_{1}}=\Theta_{1}(x) \frac{d^{2} v_{0}}{d x^{2}}+\Theta_{0}(x) \frac{d^{2} v_{1}}{d x^{2}}, \\
& \widetilde{D}_{1}=2 \frac{d v_{0}}{d x} \frac{d v_{1}}{d x}, \\
& \widetilde{E}_{1}=\Theta_{1}(x)\left(\frac{d v_{0}}{d x}\right)^{2}+2 \Theta_{0}(x) \frac{d v_{1}}{d x} \frac{d v_{0}}{d x}, \\
& \widetilde{F}_{1}=4\left(\frac{d v_{0}}{d x}\right)^{3} \frac{d v_{1}}{d x} \text {. }
\end{aligned}
$$

Solution of (23) in series form is derived as

$$
\begin{aligned}
v_{0}+v_{1}+\cdots= & f_{1}-6 \beta L^{-1}[\overbrace{A_{0}}+\overbrace{A_{1}}+\cdots] \\
& +M L^{-1}[\overbrace{B_{0}}+\overbrace{B_{1}}+\cdots] \\
& +M L^{-1}[\overbrace{C_{0}}+\overbrace{C_{1}}+\cdots] \\
\Theta_{0}+\Theta_{1}+\cdots= & f_{2}-B_{r} L^{-1}[\overbrace{D_{0}}+\overbrace{D_{1}}+\cdots] \\
& +M B_{r} L^{-1}[\overbrace{E_{0}}+\overbrace{E_{1}}+\cdots] \\
& -2 B_{r} \beta L^{-1}[\overbrace{F_{0}}+\overbrace{F_{1}}+\cdots] .
\end{aligned}
$$

The velocity and heat components up to second component are obtained by comparing both sides of (28).

Components of the lift problem are

$$
\begin{gathered}
v_{0}(x)=f_{1}, \\
\Theta_{0}(x)=f_{2},
\end{gathered}
$$

$$
\begin{aligned}
v_{1}(x)= & -6 \beta L^{-1}[\overbrace{A_{0}}]+M L^{-1}[\overbrace{B_{0}}] \\
& +M L^{-1}[\overbrace{C_{0}}], \\
\Theta_{1}(x)= & -B_{r} L^{-1}[\overbrace{D_{0}}]+M B_{r} L^{-1}[\overbrace{E_{0}}] \\
& -2 B_{r} \beta L^{-1}[\overbrace{F_{0}}], \\
v_{2}(x)= & -6 \beta L^{-1}[\overbrace{A_{1}}]+M L^{-1}[\overbrace{B_{1}}] \\
& +M L^{-1}[\overbrace{C_{1}}], \\
\Theta_{2}(x)= & -B_{r} L^{-1}[\overbrace{D_{1}}]+\Lambda B_{r} L^{-1}[\overbrace{E_{1}}] \\
& -2 B_{r} \beta L^{-1}[\overbrace{F_{1}}] .
\end{aligned}
$$

Zero component slip boundary conditions from (16) and (19) are

$$
\begin{gathered}
v_{0}=1-\Lambda\left(\frac{d v_{0}}{d x}-M \Theta_{0} \frac{d v_{0}}{d x}+2 \beta\left(\frac{d v_{0}}{d x}\right)^{3}\right), \\
\Theta_{0}=0, \quad \text { at } x=0, \\
\frac{d v_{0}}{d x}=0, \quad \Theta_{0}=1, \quad \text { at } x=1 .
\end{gathered}
$$

First component slip boundary conditions from (17) and (19) are

$$
\begin{gathered}
v_{1}=-\Lambda\left(\frac{d v_{1}}{d x}-M \Theta_{0} \frac{d v_{1}}{d x}-M \Theta_{1} \frac{d v_{0}}{d x}+6 \beta\left(\frac{d v_{0}}{d x}\right)^{2} \frac{d v_{1}}{d x}\right), \\
\Theta_{1}=0, \quad \text { at } x=0, \\
\frac{d v_{1}}{d x}=0, \quad \Theta_{1}=0, \quad \text { at } x=1 .
\end{gathered}
$$

Second component slip boundary conditions from (17) and (19) are

$$
\begin{gathered}
v_{2}=-\Lambda\left[\frac{d v_{2}}{d x}-M\left(\Theta_{0} \frac{d v_{2}}{d x}+\Theta_{1} \frac{d v_{1}}{d x}+\Theta_{2} \frac{d v_{0}}{d x}\right)\right. \\
\left.+6 \beta\left(\left(\frac{d v_{0}}{d x}\right)^{2} \frac{d v_{2}}{d x}+\left(\frac{d v_{1}}{d x}\right)^{2} \frac{d v_{0}}{d x}\right)\right], \\
\Theta_{2}=0, \quad \text { at } x=0, \\
\frac{d v_{2}}{d x}=0, \quad \Theta_{2}=0, \quad \text { at } x=1 .
\end{gathered}
$$

Inserting slip boundary conditions from (35) and (36) into (29) and (30), $v_{0}(x)$ and $\Theta_{0}(x)$ are

$$
\begin{aligned}
v_{0}(x) & =\left(1+\Lambda S_{t}+2 \beta \Lambda S_{t}^{3}\right)-\left(S_{t}\right) x+\left(\frac{S_{t}}{2}\right) x^{2}, \\
\Theta_{0}(x) & =x .
\end{aligned}
$$




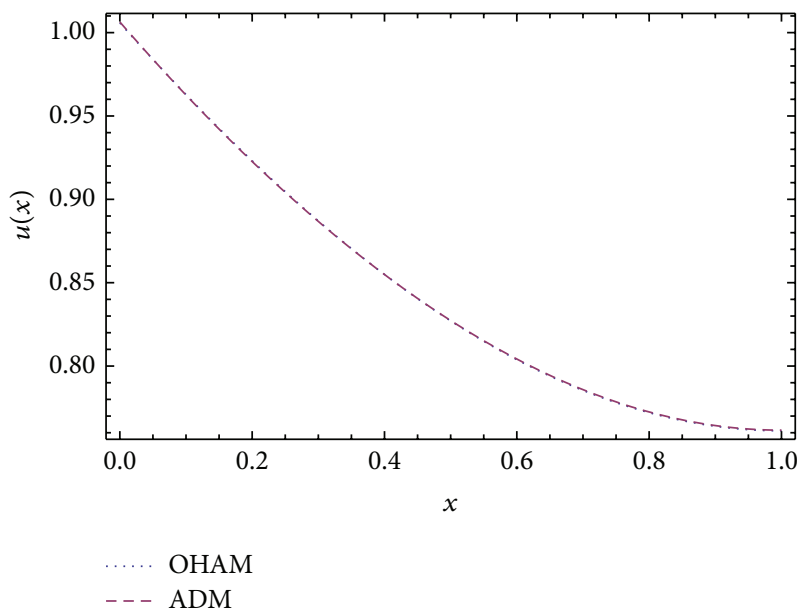

(a)

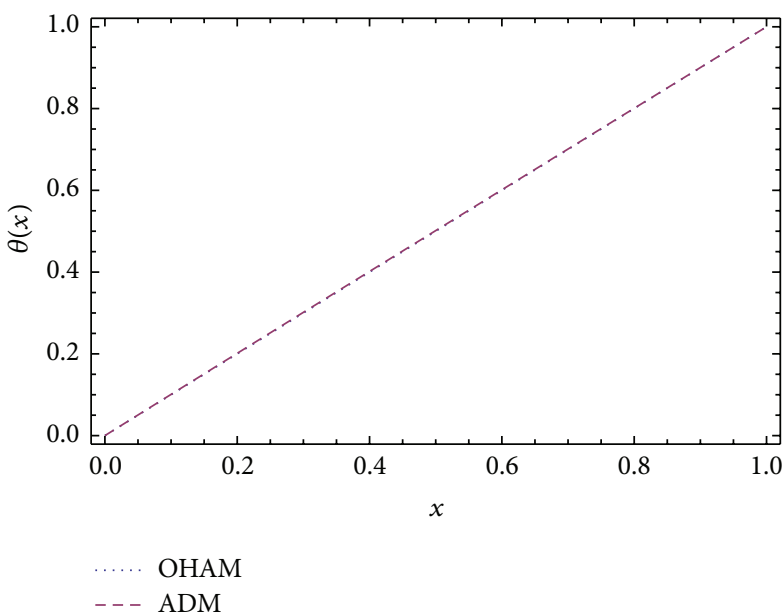

(b)

FIgURE 2: Comparison of ADM and OHAM methods for lift velocity profile (a) and temperature distribution (b). $S_{t}=0.5, M=0.1, \beta=0.3$, $\Lambda=0.01, B_{r}=4, C_{1}=0.212619, S_{t}=0.1, M=0.1, \beta=0.3, \Lambda=0.01, B_{r}=4, C_{1}=-0.702416, C_{2}=-0.24397, C_{3}=0.01611$, $C_{4}=-0.016823 . C_{2}=-0.03461, C_{3}=-4.49647$, and $C_{4}=-16.42906$.

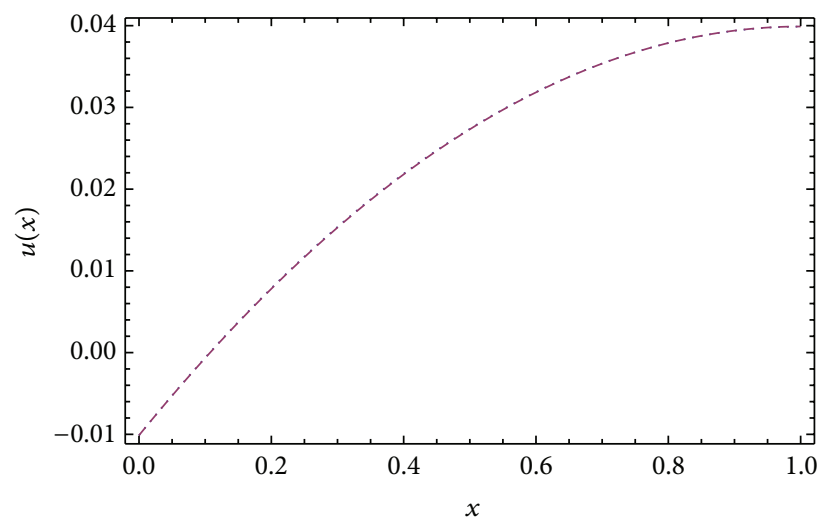

OHAM

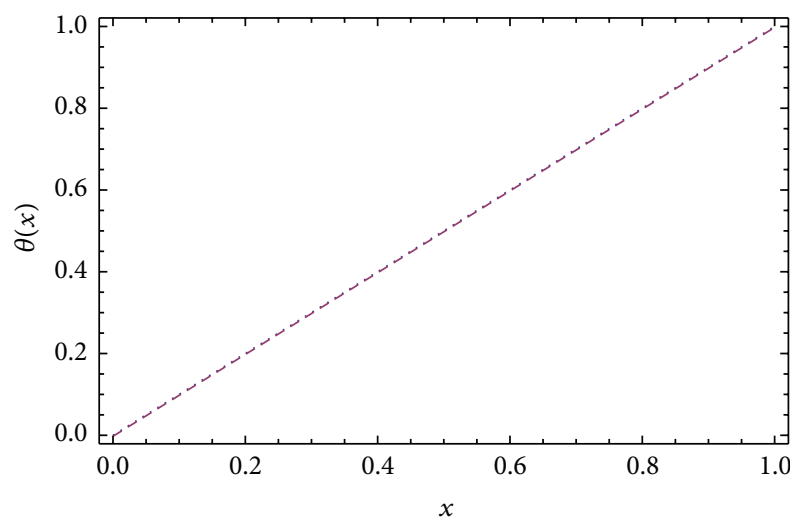

OHAM

$$
\text { -- - ADM }
$$

(a)

FIGURE 3: Comparison of ADM and OHAM methods for drainage velocity profile (a) and temperature distribution (b). $S_{t}=0.1, M=0.01$, $\beta=0.3, \Lambda=0.1, B_{r}=0.4, C_{1}=-0.000019, S_{t}=0.1, M=0.01, \beta=0.3, \Lambda=0.1, B_{r}=0.4, C_{1}=-0.073388, C_{2}=0.000069, C_{3}=1728.447608$, $C_{4}=152.167755, C_{2}=0.049829, C_{3}=-1.123666$, and $C_{4}=-0.0230394$.

Inserting slip boundary conditions from (37) and (38) into (31) and (32), $v_{1}(x)$ and $\Theta_{1}(x)$ are

$$
\begin{aligned}
v_{1}(x)= & \left(2 \beta \Lambda S_{t}^{3}+12 \beta^{2} \Lambda S_{t}^{5}\right)+\left(2 \beta S_{t}^{3}\right) x \\
& -\left(\frac{M S_{t}}{2}+3 \beta S_{t}^{3}\right) x^{2}+\left(\frac{M S_{t}}{3}+2 \beta S_{t}^{3}\right) x^{3} \\
& -\left(\frac{1}{2} \beta S_{t}^{3}\right) x^{4}, \\
\Theta_{1}(x)= & \left(\frac{1}{4} B_{r} S_{t}^{2}-\frac{1}{20} M B_{r} S_{t}^{2}+\frac{1}{3} \beta B_{r} S_{t}^{4}\right) x
\end{aligned}
$$




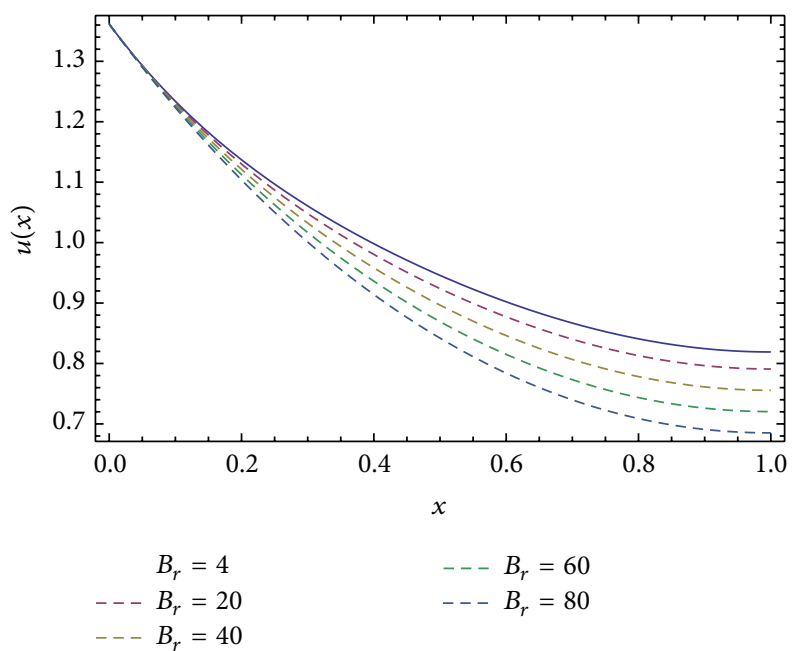

(a)

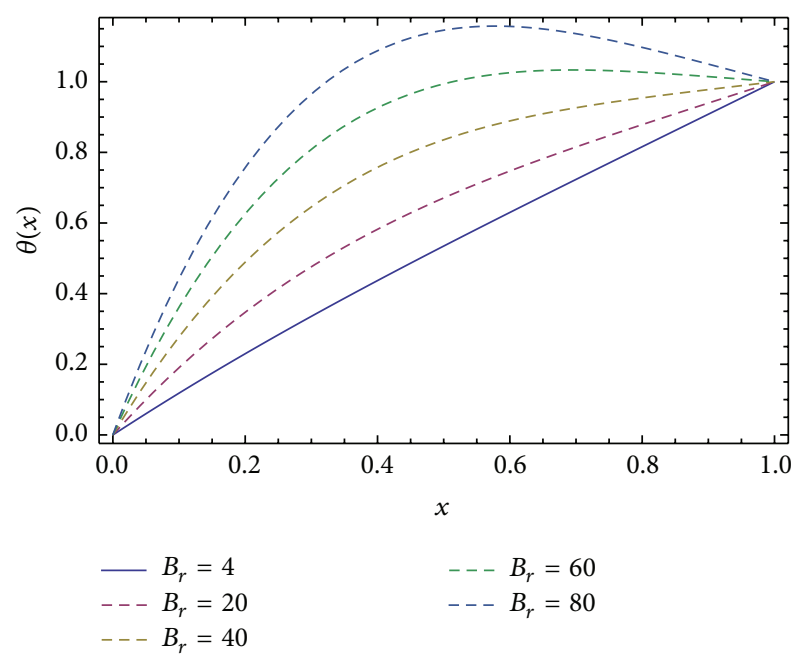

(b)

Figure 4: Brinkman number on the lift velocity (a) and temperature distribution (b) when $S_{t}=1, \Lambda=0.4, M=0.1$, and $\beta=0.3$ and $S_{t}=0.5$, $\Lambda=0.4, M=0.1$, and $\beta=0.3$.

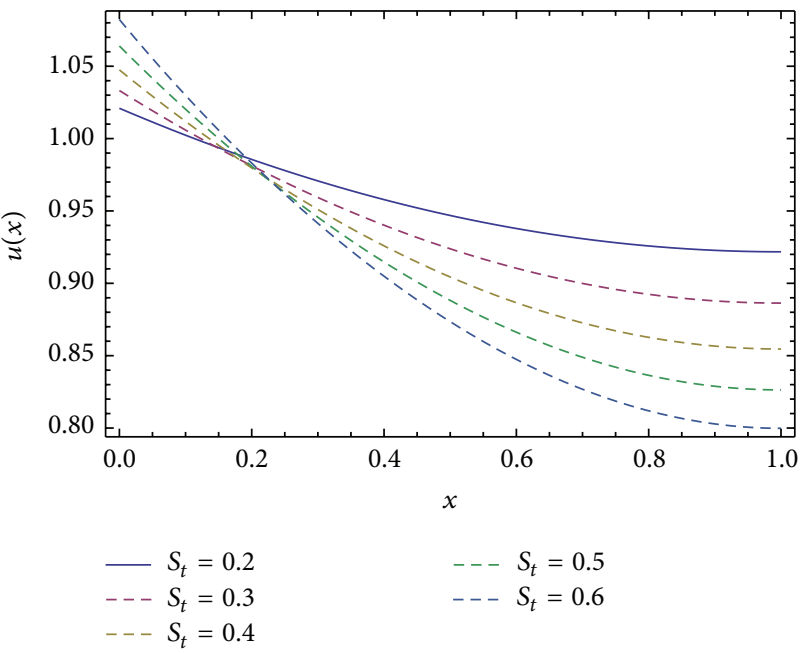

(a)

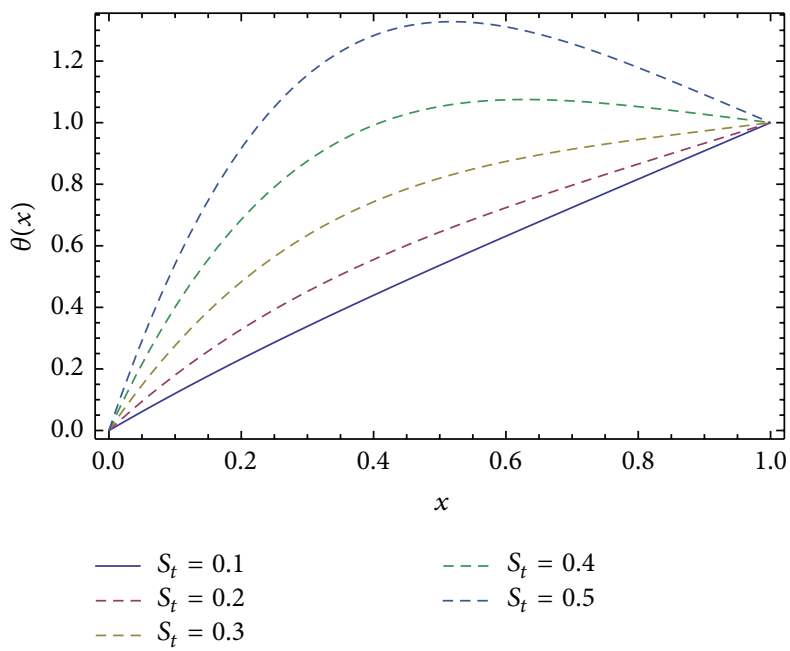

(b)

FIGURE 5: Effect of the stock number on lift velocity (a) and temperature distribution (b) when $M=0.01, \beta=0.3, \Lambda=0.1$, and $B_{r}=4$ and $\beta=0.3, M=0.01$, and $B_{r}=100$.

The terms $v_{2}(x)$ and $\Theta_{2}(x)$ are too large to be written above; therefore, their expression is mentioned graphically.

\section{Formulation of Drainage Problem}

The geometry and assumptions of the problem are the same as in previous problem. Consider a film of non-Newtonian liquid draining at volume flow rate $Q$ down the vertical belt. The belt is stationary and the fluid drains down the belt due to gravity. The gravity in this case is opposite to the previous case. Therefore, the stock number is positively mentioned in (14). The coordinate system is selected the same as in previous case. Assume the flow is steady and laminar while external pressure is neglected. Consider fluid shear forces keep the gravity balanced and the film thickness remains constant.
Modeled slip boundary conditions for drainage problem are

$$
\begin{aligned}
v & =-\gamma T_{x y}, \quad \text { at } x=0, \\
\frac{d v}{d x} & =0, \quad \text { at } x=1 .
\end{aligned}
$$

Making use of nondimensional variables the slip boundary conditions in (42) are

$$
\begin{array}{r}
v_{n}=-\Lambda\left(\frac{d v_{n}}{d x}-M \Theta \frac{d v_{n}}{d x}+2 \beta\left(\frac{d v_{n}}{d x}\right)^{3}\right), \\
\text { at } x=0,
\end{array}
$$

$\frac{d v_{n}}{d x}=0, \quad$ at $x=1$, when $n=0,1,2,3, \ldots$ 


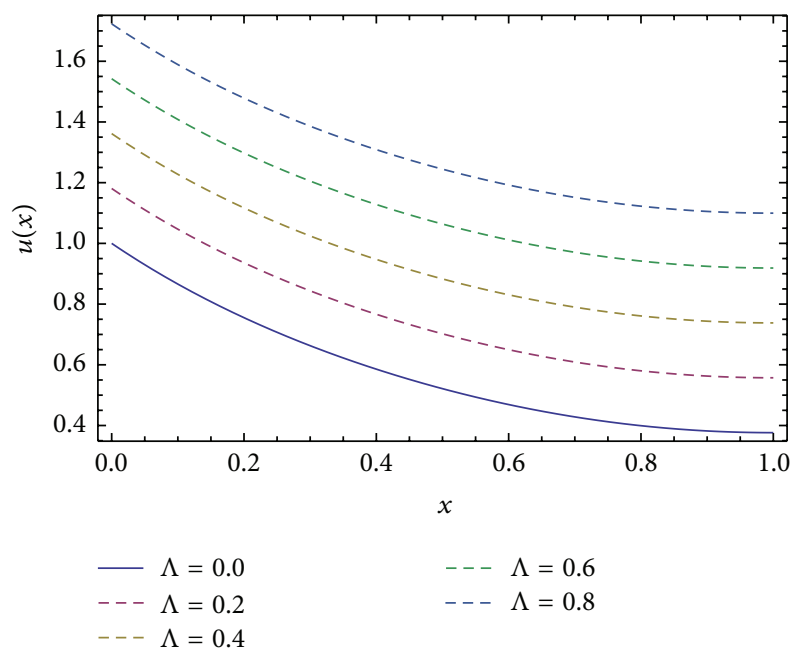

FIGURE 6: Effect of slip parameter on the lift velocity profile when $S_{t}=1, M=0.1, \beta=0.3$, and $B_{r}=50$.

For heat, the boundary conditions are identical as given in (36), (38), and (40) regarding both the problems.

\section{Solution of Drainage Problem}

6.1. The ADM Solution. By making use of ADM in (14) and (15), the Adomian polynomials in (24)-(27) for both problems are the same. The different velocity components are obtained as follows.

Components of Problem. The boundary conditions of first and second components for drainage velocity profile are the same as given in (37). The boundary conditions for temperature distribution are also the same as given in (38), but the solution of these components is different, dependent on the different velocity profile of drainage and lift problems. The terms $v_{2}(x)$ and $\Theta_{2}(x)$ are too large to be written above; therefore, their expression is mentioned graphically.

Inserting slip boundary conditions from (45) and from (18) and (19) in (29)-(34) the different components solution is obtained as

$$
\begin{gathered}
v_{0}(x)=\frac{1}{2}\left(2 S_{t} x-S_{t} x^{2}\right), \\
\Theta_{0}(x, t)=x, \\
v_{1}(x)=\left(-\frac{1}{3} M^{2} S_{t}-\beta S_{t}^{3}\right) x \\
+\left(\frac{\Lambda S_{t}}{2}+\frac{3 \beta S_{t}^{3}}{2}\right) x^{2} \\
+\left(\frac{M^{2} S_{t}}{6}-\frac{\Lambda S_{t}}{3}-\beta S_{t}^{3}\right) x^{3} \\
+\left(-\frac{1}{24} M^{2} S_{t}+\frac{\beta S_{t}^{3}}{4}\right) x^{4},
\end{gathered}
$$

TABLE 1: Comparison of present work and existing work [23] for lift velocity profile when $m=S_{t}=0.5, M=0, \beta=0.6, \Lambda=0, \alpha=1$.

\begin{tabular}{lccc}
\hline$x$ & Present work & Existing work & Absolute error \\
\hline 0.0 & 1 & 1 & 0 \\
0.1 & 0.95485367 & 0.95485367 & 0 \\
0.2 & 0.91553824 & 0.91553824 & 0 \\
0.3 & 0.88114335 & 0.88114335 & 0 \\
0.4 & 0.85118976 & 0.85118976 & $0.148 \times 10^{-14}$ \\
0.5 & 0.82550781 & 0.82550781 & 0 \\
0.6 & 0.80413216 & 0.80413216 & $1.11 \times 10^{-29}$ \\
0.7 & 0.78721265 & 0.787212652 & 0 \\
0.8 & 0.77494144 & 0.77494144 & $-1.11 \times 10^{-29}$ \\
0.9 & 0.76749627 & 0.767496272 & 0 \\
1.0 & 0.765 & 0.765 & $-1.11 \times 10^{-29}$ \\
\hline
\end{tabular}

$$
\begin{aligned}
\Theta_{1}(x)= & \left(\frac{1}{4} B_{r} S_{t}^{2}-\frac{1}{20} \Lambda B_{r} S_{t}^{2}+\frac{1}{6} \beta B_{r} S_{t}^{4}\right) x \\
& +\left(-\frac{1}{2} B_{r} S_{t}^{2}-\frac{1}{2} \beta B_{r} S_{t}^{4}\right) x^{2} \\
& +\left(\frac{1}{3} B_{r} S_{t}^{2}+\frac{1}{6} \Lambda B_{r} S_{t}^{2}+\frac{2}{3} \beta B_{r} S_{t}^{4}\right) x^{3} \\
& +\left(-\frac{1}{12} B_{r} S_{t}^{2}-\frac{1}{6} \Lambda B_{r} S_{t}^{2}-\frac{1}{2} \beta B_{r} S_{t}^{4}\right) x^{4} \\
& +\left(\frac{1}{20} \Lambda B_{r} S_{t}^{2}+\frac{1}{5} \beta B_{r} S_{t}^{4}\right) x^{5} \\
& +\left(-\frac{1}{30} \beta B_{r} S_{t}^{4}\right) x^{6} .
\end{aligned}
$$

In the existence work [23] $m$ is used as gravitational parameter instead of stock number $S_{t}$ in the present work. Magnetic parameter is defined as $M$ in the existing work and in the present work $M$ is embedding parameter. If we put magnetic parameter $=0$, slip parameter $\Lambda=0$ in the existing work and embedding parameter $M=0$, slip parameter $\Lambda=0$ in present work, then comparison of existing and present work is as shown in Table 1.

OHAM solution of the present work has been obtained and used only for comparison through Tables 1, 2, 3, 4, and 5.

\section{Results and Discussion}

In this study, the heat transfer of a third grade fluid on thin film flow has been examined. The geometry of lift and drainage problems has been shown in Figures 1(a) and 1(b), respectively. The velocity and heat transfer analysis for both lift and drainage problems have been investigated under the influence of stock number $S_{t}$, slip parameter $\Lambda$, the Brinkman number $B_{r}$, non-Newtonian parameter $\beta$, and viscosity parameter $M$. The effects of these physical parameters have been discussed in Figures 2-13. The OHAM solution of the present work has been shown graphically and numerically 


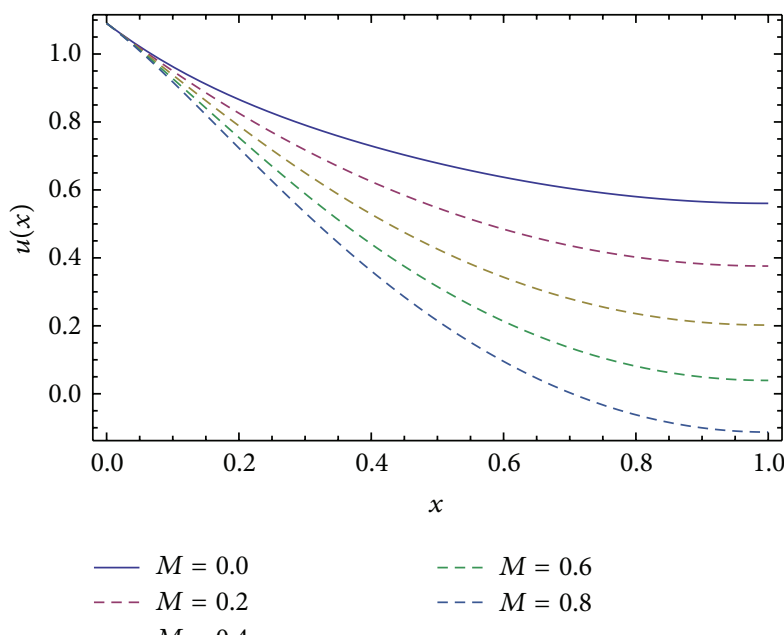

(a)

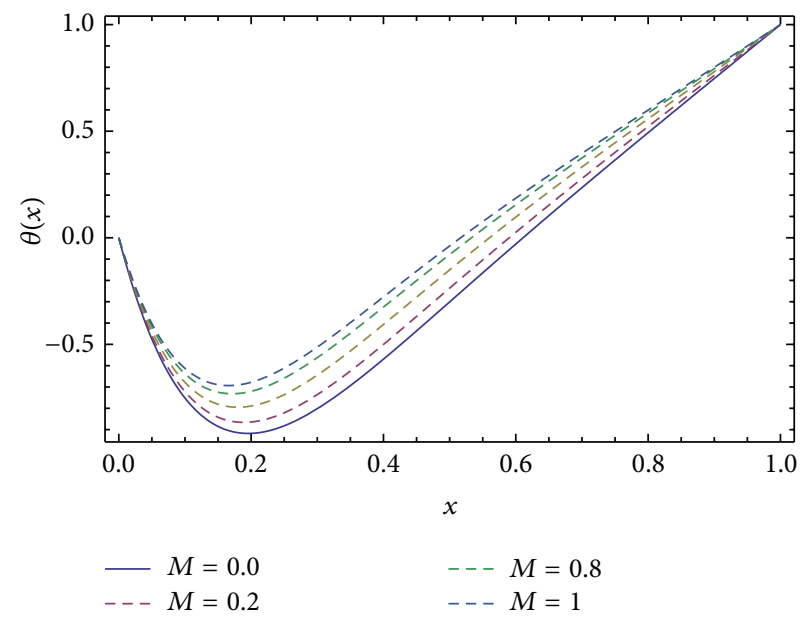

(b)

FIGURE 7: The effect of viscosity parameter on lift velocity (a) and temperature distribution (b) when $B_{r}=40, \Lambda=0.1, \beta=0.3$, and $S_{t}=0.5$ and $B_{r}=10, \beta=0.6$, and $S_{t}=1$.

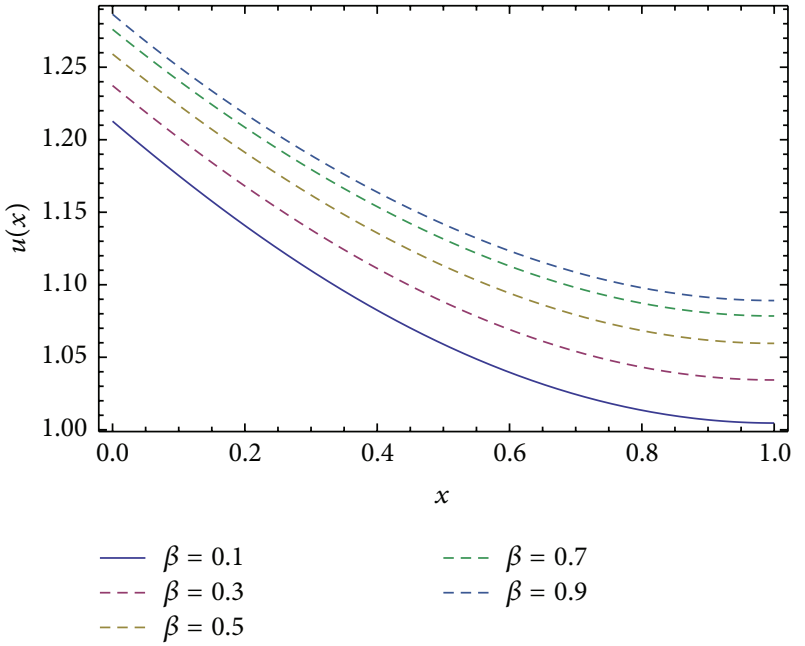

(a)

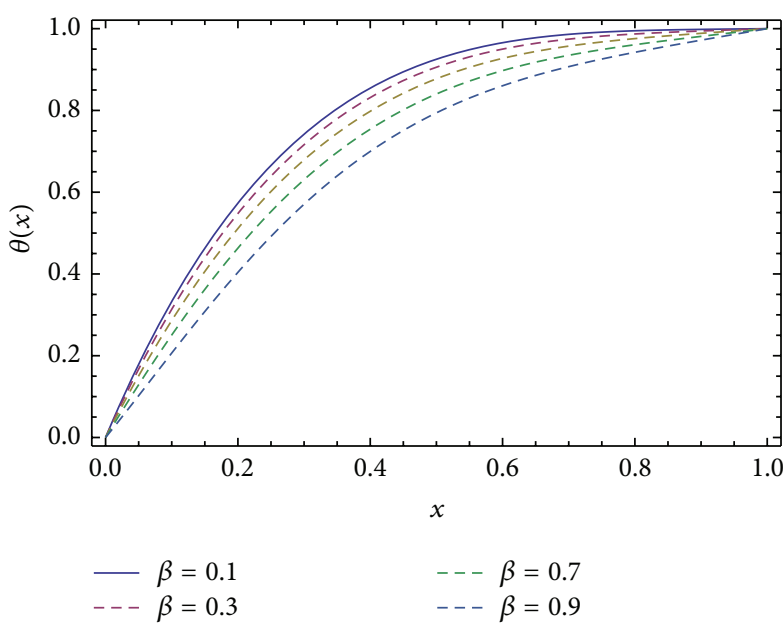

(b)

Figure 8: Effect of $\beta$ on lift velocity (a) and temperature distribution (b) when $M=0.1, S_{t}=0.4, \Lambda=0.5$, and $B_{r}=50$.

only for comparison. The comparison of analytical methods ADM and OHAM of the present work for lift velocity and heat transfer analysis is shown in Figures 2(a) and 2(b). Figures 3(a) and 3(b) show the comparison of ADM and OHAM for drainage velocity and temperature distribution. Effect of the Brinkman number $B_{r}$, for lift velocity profile, has been shown in Figure 4(a). Behavior of the lift velocity field $v$ can be seen when the velocity of fluid is maximum at the surface of the belt while it is minimum at the surface of the fluid. It has been found out that the velocity of the fluid decreases for large value of $B_{r}$ as compared to small values of $B_{r}$. The observation of Brinkman number $B_{r}$ associated with heat in lift problem has been countered in Figure $4(\mathrm{~b})$. Since $B_{r}$ is related with the viscous dissipation term in energy equation, higher values of the $B_{r}$ should essentially lead to an increase in amount of heat being generated by the shear forces in the fluid leading to increase in the fluid temperature.

In Figure 5(a), we observed that the velocity decreases with an increase in the stock number $S_{t}$; due to friction force, the effect of stock number seems to be smaller near the belt. It can be seen that there is a point in the domain, where the velocity of the fluid becomes approximately identical for different values of stock number $S_{t}$. The reason is that the friction of the belt becomes negligible at this point. On increasing stock number $S_{t}$, after this point in lifting flow, the velocity decreases due to negligible friction. The effect of stock number $S_{t}$ on temperature distribution has been illustrated in Figure 5(b). It has been observed that the temperature $\Theta$ increases steadily by increasing $S_{t}$. In Figure 6, it has been noticed that the speed of the fluid near 


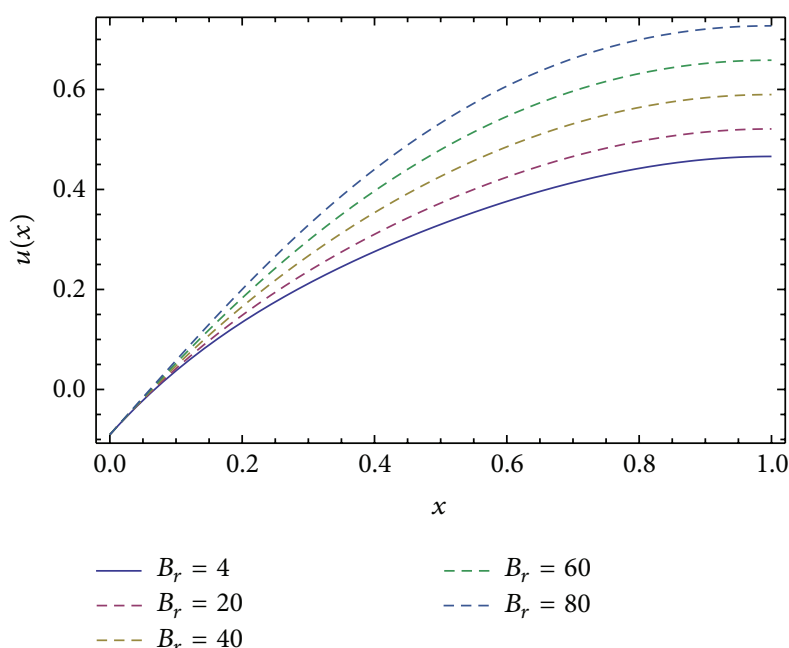

(a)

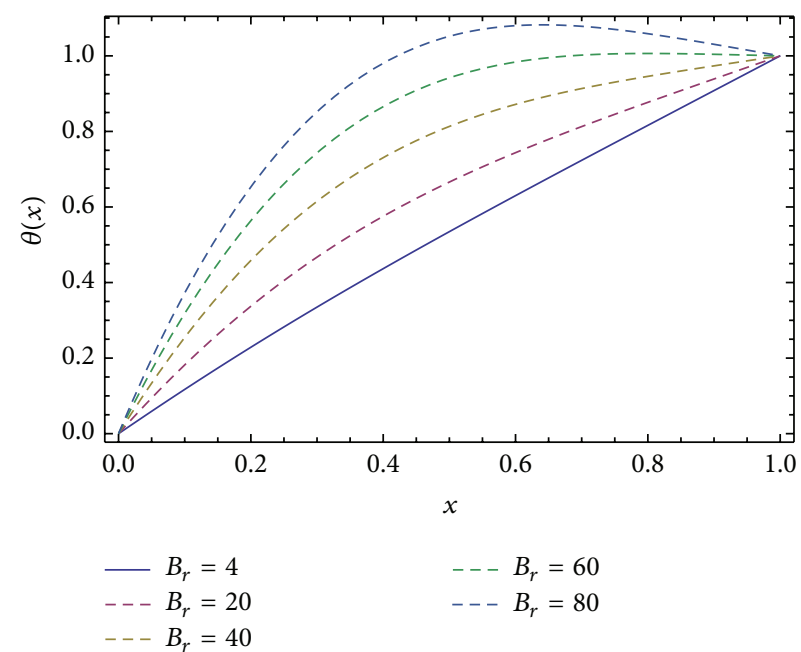

(b)

Figure 9: Drainage velocity (a) and heat distribution (b) for Brickman number when $S_{t}=1, \Lambda=0.1, M=0.2$, and $\beta=0.3$ and $M=0.3$, $S_{t}=0.5, \beta=0.5$, and $\Lambda=0.1$.

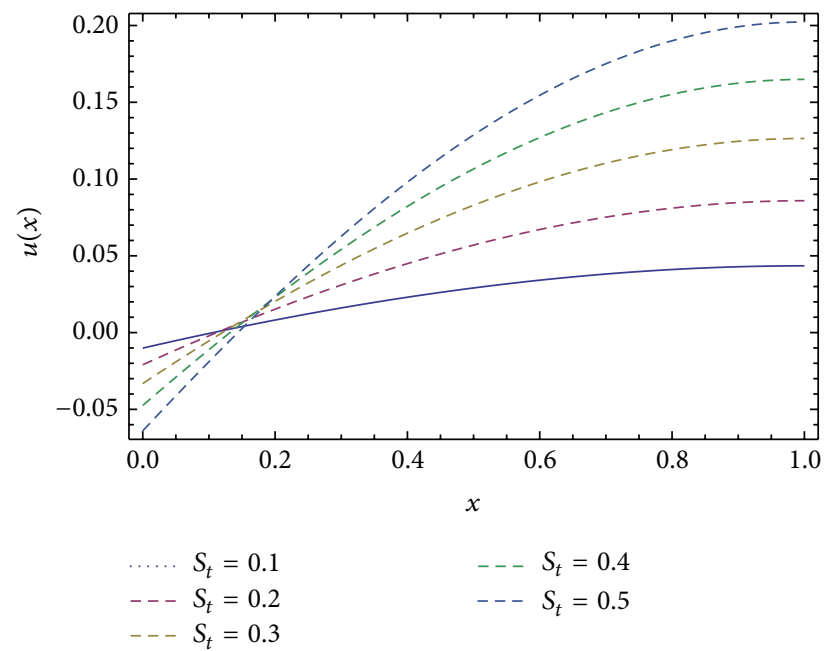

(a)

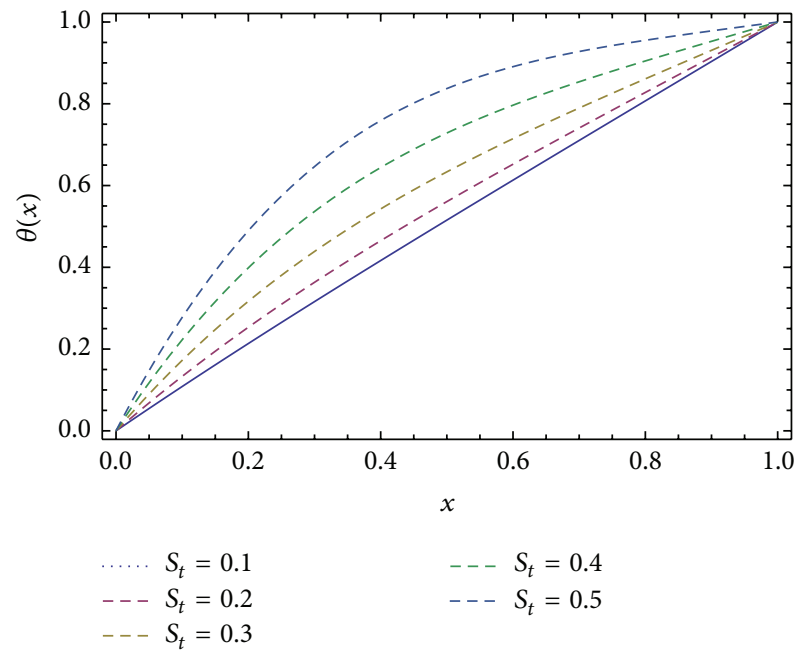

(b)

FIGURE 10: Effect of stock number on drainage velocity profile (a) and temperature distribution (b) when $M=0.2, \beta=0.3, \Lambda=0.1$, and $B_{r}=40$.

the belt is greater than the speed at the surface. When we increase the slip parameter, then, due to decrease in friction force, the velocity of the fluid decreases gradually towards the surface of the belt. The effect of viscosity parameter $M$ on lift velocity $v$ has been shown in Figure 7(a). The speed of flow decreases with increasing $M$. It can also be seen that the thickness of thin film increases in case of dilatant fluids and decreases in pseudoplastic fluids. In Figure 7(b), increase in viscosity parameter $M$ results in increasing temperature distribution steadily. Figure 8(a) indicates the influence of non-Newtonian effect $\beta$ on lift velocity profile.

For small values of $\beta$, the velocity profile differs little from the Newtonian one. However, when $\beta$ is increased, these profiles become more flatten showing the shear thinning effect. Increase in $\beta$ results in decreasing temperature distribution as shown in Figure 8(b). The drain velocity increases with increase in Brinkman number as shown in Figure 9(a). Figure 9(b) specifies the effect of $B_{r}$ for drain temperature distribution. The temperature distribution increases as the $B_{r}$ increases and becomes more trampled for higher value of $B_{r}$. In Figure 10(a), the effect of stock number $S_{t}$ has been shown for drainage flow. It can be seen that there is a point near the belt, where the velocity of the fluid becomes approximately the same for different values of stock number $S_{t}$ because friction of the belt becomes negligible at this point. On increasing the stock number $S_{t}$, after this point, the curvature of velocity increases due to negligible friction. The effect of stock number $S_{t}$ on temperature distribution 


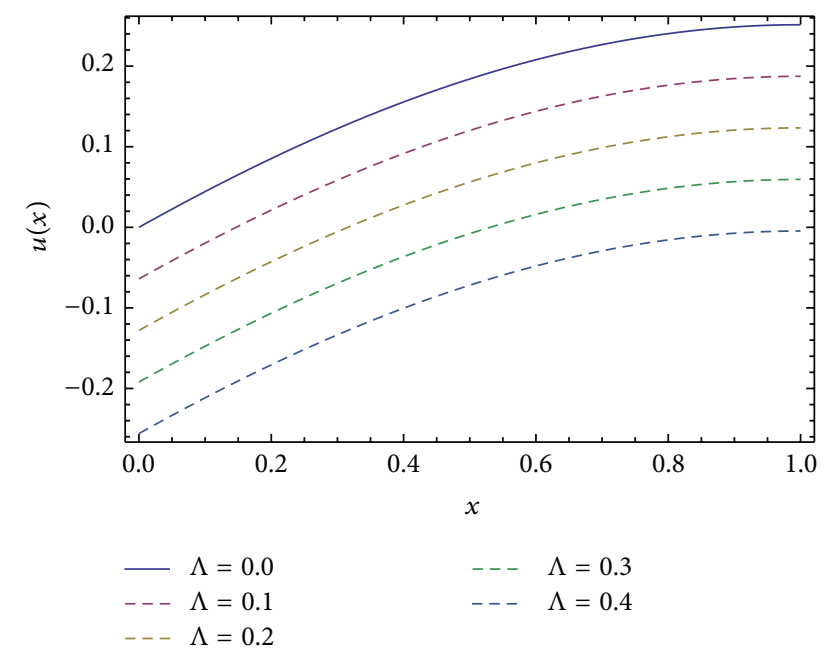

FIGURE 11: Drain velocity profile for different values of slip parameter when $M=0.1, S_{t}=0.5, \beta=0.3$, and $B_{r}=40$.

TABLE 2: Comparison of OHAM and ADM for lift velocity profile when $S_{t}=0.5, M=0.1, \beta=0.3, \Lambda=0.01, B_{r}=4, C_{1}=0.212619$, $C_{2}=-0.243971, C_{3}=0.016110, C_{4}=-0.0168232$.

\begin{tabular}{lccc}
\hline$x$ & OHAM & ADM & Absolute error \\
\hline 0.0 & 1.00586 & 1.0064 & $0.543 \times 10^{-3}$ \\
0.1 & 0.962821 & 0.962544 & $0.277 \times 10^{-3}$ \\
0.2 & 0.923093 & 0.922658 & $0.435 \times 10^{-3}$ \\
0.3 & 0.887013 & 0.886739 & $0.274 \times 10^{-3}$ \\
0.4 & 0.854908 & 0.854893 & $0.148 \times 10^{-4}$ \\
0.5 & 0.827086 & 0.827304 & $0.217 \times 10^{-3}$ \\
0.6 & 0.803834 & 0.804202 & $0.367 \times 10^{-3}$ \\
0.7 & 0.785409 & 0.785838 & $0.428 \times 10^{-3}$ \\
0.8 & 0.77204 & 0.772463 & $0.423 \times 10^{-3}$ \\
0.9 & 0.763914 & 0.764303 & $0.389 \times 10^{-3}$ \\
1.0 & 0.76118 & 0.761549 & $0.369 \times 10^{-3}$ \\
\hline
\end{tabular}

TABLE 3: Comparison of OHAM and ADM for lift heat distribution when $S_{t}=0.1, M=0.1, \beta=0.3, \Lambda=0.01, B_{r}=4, C_{1}=-0.70242$, $C_{2}=-0.03461, C_{3}=-4.49647, C_{4}=-16.42906$.

\begin{tabular}{lccc}
\hline$x$ & OHAM & ADM & Absolute error \\
\hline 0.0 & 0 & 0 & $0.840 \times 10^{-3}$ \\
0.1 & 0.09998 & 0.10083 & $0.135 \times 10^{-2}$ \\
0.2 & 0.19998 & 0.20133 & $0.159 \times 10^{-2}$ \\
0.3 & 0.29998 & 0.30157 & $0.163 \times 10^{-2}$ \\
0.4 & 0.39998 & 0.40162 & $0.152 \times 10^{-2}$ \\
0.5 & 0.49998 & 0.50151 & $0.130 \times 10^{-2}$ \\
0.6 & 0.59998 & 0.60129 & $0.101 \times 10^{-2}$ \\
0.7 & 0.69998 & 0.70101 & $0.693 \times 10^{-3}$ \\
0.8 & 0.79999 & 0.80068 & $0.423 \times 10^{-3}$ \\
0.9 & 0.863914 & 0.90034 & $0.349 \times 10^{-3}$ \\
1.0 & 1.000000 & 1.000000 & $0.294 \times 10^{-19}$ \\
\hline
\end{tabular}

TABLE 4: Comparison of OHAM and ADM for drainage velocity profile when $S_{t}=0.1, M=0.01, \beta=0.3, \Lambda=0.1, B_{r}=0.4$, $C_{1}=-0.00002, C_{2}=0.00007, C_{3}=1728.44761, C_{4}=152.16776$.

\begin{tabular}{lccc}
\hline$x$ & OHAM & ADM & Absolute error \\
\hline 0.0 & -0.01012 & -0.01012 & 0.0 \\
0.1 & -0.00062 & -0.00067 & $0.461 \times 10^{-4}$ \\
0.2 & 0.00789 & 0.00781 & $0.702 \times 10^{-4}$ \\
0.3 & 0.01538 & 0.01531 & $0.768 \times 10^{-4}$ \\
0.4 & 0.02188 & 0.02181 & $0.708 \times 10^{-4}$ \\
0.5 & 0.02738 & 0.02733 & $0.561 \times 10^{-4}$ \\
0.6 & 0.03188 & 0.03185 & $0.371 \times 10^{-4}$ \\
0.7 & 0.03538 & 0.03536 & $0.168 \times 10^{-4}$ \\
0.8 & 0.03788 & 0.037881 & $0.920 \times 10^{-8}$ \\
0.9 & 0.03938 & 0.03939 & $0.134 \times 10^{-3}$ \\
1.0 & 0.03988 & 0.03989 & $0.182 \times 10^{-3}$ \\
\hline
\end{tabular}

TABLE 5: Comparison of OHAM and ADM for drain heat distribution when $S_{t}=0.1, M=0.01, \beta=0.3, \Lambda=0.1, B_{r}=0.4$, $C_{1}=-0.07339, C_{2}=0.049829, C_{3}=-1.12367, C_{4}=-0.02304$.

\begin{tabular}{lccc}
\hline$x$ & OHAM & ADM & Absolute error \\
\hline 0.0 & 0 & 0 & 0 \\
0.1 & 0.100082 & 0.100081 & $0.818 \times 10^{-6}$ \\
0.2 & 0.200131 & 0.20013 & $0.115 \times 10^{-5}$ \\
0.3 & 0.300154 & 0.300153 & $0.118 \times 10^{-5}$ \\
0.4 & 0.400158 & 0.400157 & $0.107 \times 10^{-5}$ \\
0.5 & 0.500147 & 0.500146 & $0.887 \times 10^{-6}$ \\
0.6 & 0.600126 & 0.600125 & $0.689 \times 10^{-6}$ \\
0.7 & 0.700098 & 0.700097 & $0.501 \times 10^{-6}$ \\
0.8 & 0.800067 & 0.800066 & $0.326 \times 10^{-6}$ \\
0.9 & 0.900034 & 0.900033 & $0.161 \times 10^{-6}$ \\
1.0 & 1.000000 & 1.000000 & $0.261 \times 10^{-18}$ \\
\hline
\end{tabular}

is illustrated in Figure 10(b). In Figure 11, it is noticed that the speed of the fluid near the belt is smaller than the speed at the surface. When we increase the slip parameter, the velocity of the fluid increases because the friction goes on decreasing. It has been observed that the temperature $\Theta$ increases monotonically on increasing $S_{t}$. Figure 12(a) illustrates the effect of variable viscosity parameter $M$ on the drain velocity profile. For higher values of viscosity parameter $M$ the velocity of fluid increases gradually towards the surface of the fluid. Increase in viscosity parameter $M$ causes increase in temperature field gradually as shown in Figure 12(b). The effect of non-Newtonian parameter $\beta$ totally depends on the shear thining effect as shown in Figure 13(a). Increase in $\beta$ results in increasing speed of the drain velocity profile but increase in $\beta$ decreases temperature profile dependent on the shear thinning and thickening properties of fluid film as shown in Figure 13(b).

\section{Conclusion}

We have investigated the temperature dependent viscosity of a third grade thin film fluid flow subject to lifting and 


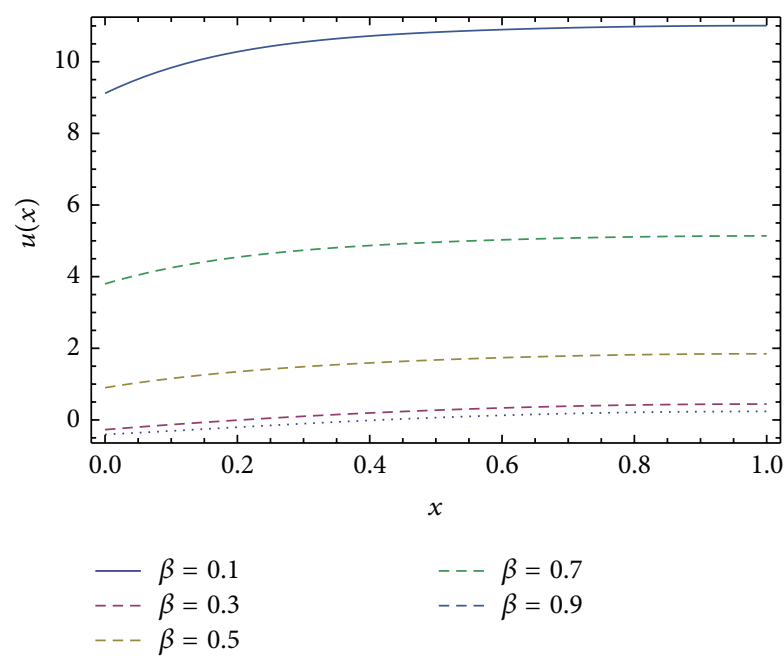

(a)

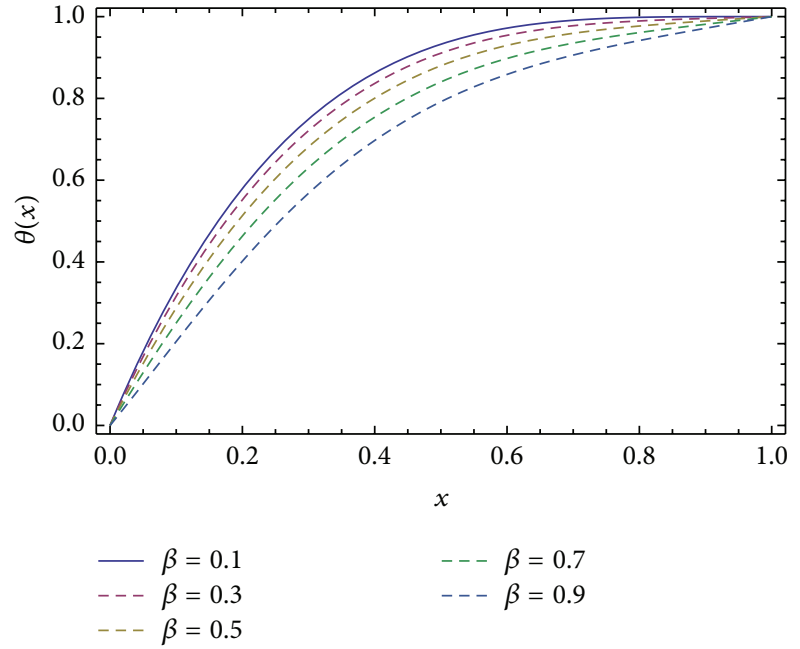

(b)

Figure 12: The effect of non-Newtonian $\beta$ on velocity profile (a) and temperature distribution (b) when $M=0.2, S_{t}=1, \Lambda=0.3$, and $B_{r}=50$ and $M=0.3, S_{t}=0.5, \Lambda=0.1$, and $B_{r}=50$.

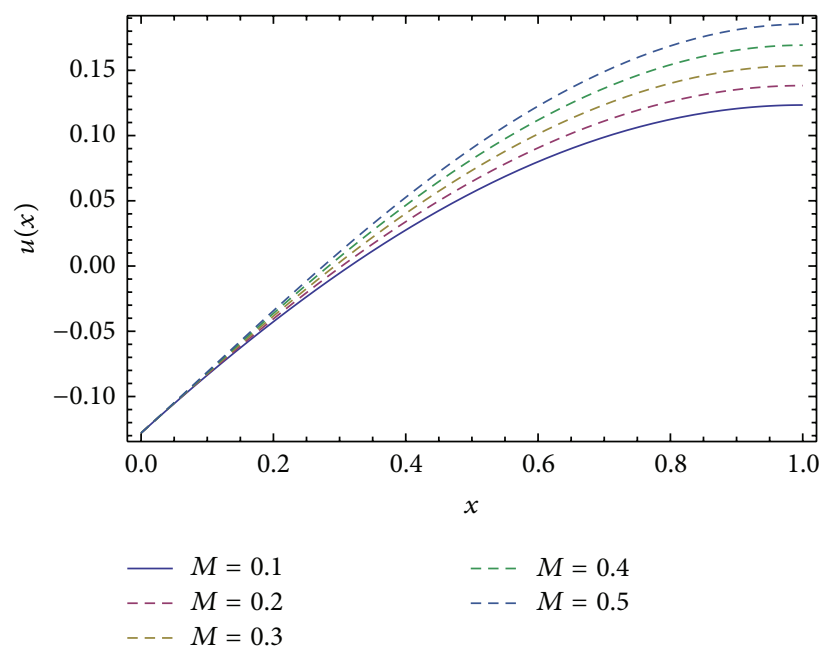

(a)

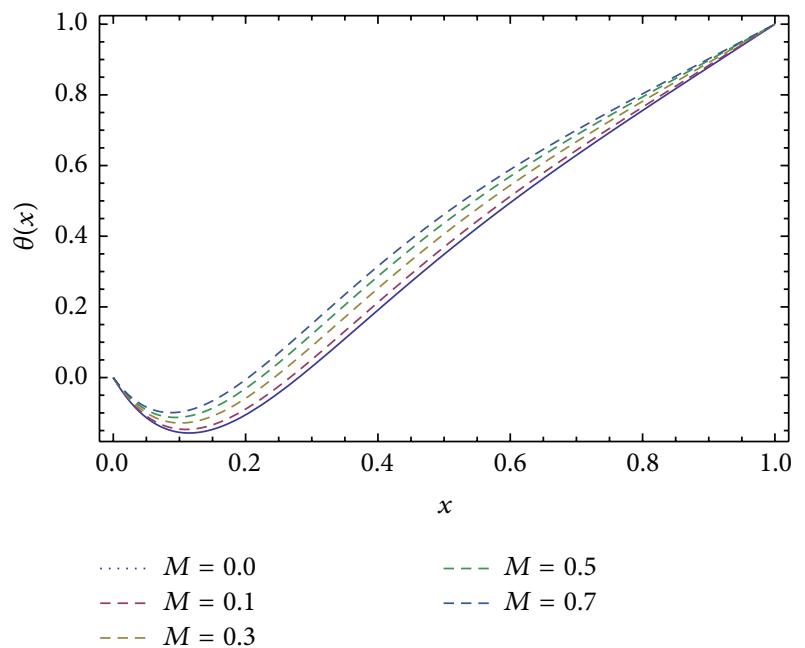

(b)

FIGURE 13: Effect of the viscosity parameter $M$ on the drainage velocity (a) and temprature (b) when $S_{t}=0.5, \beta=0.3, \Lambda=0.2$, and $B_{r}=40$ and $S_{t}=1, \beta=0.5$, and $B_{r}=10$.

drainage of fluid. Problems have been solved analytically by using Adomian Decomposition Method (ADM). The comparison of ADM and Optimal Homotopy Asymptotic Method (OHAM) has been derived graphically and numerically. Expression for velocity fields and temperature distribution has been presented and sketched. These solutions are valid not only for small but also for large values of emerging parameters. The observation of Brinkman number $B_{r}$ associated with heat is countered in both lift and drainage problems. Since $B_{r}$ is related with the viscous dissipation term in heat equation, higher values of the $B_{r}$ should essentially lead to an increase in the amount of heat being generated by the shear forces in the fluid leading to increase in the fluid temperature. It has been observed that the temperature $\Theta$ increases monotonically on increasing $S_{t}$. The speed of flow decreases with increasing viscosity parameter $M$. Increase in $M$ increases the temperature distribution. It can also be seen that the thickness of thin film increases in case of dilatant fluids and decreases in pseudoplastic fluids. According to the best of our knowledge, no research has been carried out yet regarding our study. This is our first attempt to handle this problem with variable viscosity and slip boundary conditions.

\section{Conflict of Interests}

The authors declare that there is no conflict of interests regarding the publication of this paper. 


\section{Acknowledgment}

The authors would like to thank Universiti Teknologi PETRONAS for the financial support.

\section{References}

[1] D. Goussis and R. E. Kelly, "Effects of viscosity variation on the stability of film flow down heated or cooled inclined surfaces: long-wavelength analysis," The Physics of Fluids, vol. 28, no. 11, pp. 3207-3214, 1985.

[2] D. A. Goussis and R. E. Kelly, "Effects of viscosity variation on the stability of a liquid film flow down heated or cooled inclined surfaces, finite wavelength analysis," Physics of Fluids, vol. 30, pp. 974-982, 1987.

[3] C.-C. Hwang and C.-I. Weng, "Non-linear stability analysis of film flow down a heated or cooled inclined plane with viscosity variation," International Journal of Heat and Mass Transfer, vol. 31, pp. 1775-1784, 1988.

[4] B. Reisfeld and S. G. Bankoff, "Nonlinear stability of a heated thin liquid film with variable viscosity," Physics of Fluids A, vol. 2, pp. 2066-2067, 1990.

[5] M. C. Wu and C. C. Hwang, "Nonlinear theory of film rupture with viscosity variation," International Communications in Heat and Mass Transfer, vol. 18, pp. 705-713, 1991.

[6] A. Sansom, J. R. King, and D. S. Riley, "Degenerate-diffusion models for the spreading of thin non-isothermal gravity currents," Journal of Engineering Mathematics, vol. 48, no. 1, pp. 4368, 2004.

[7] A. R. A. Khaled and K. Vafai, "Hydrodynomic Squeezed flow and heat transfer over a sensor surface," International Journal of Engineering Science, vol. 42, pp. 509-519, 2004.

[8] S. Nadeem and M. Awais, "Thin film flow of an unsteady shrinking sheet through porous medium with variable viscosity," Physics Letters A, vol. 372, pp. 4965-4972, 2008.

[9] A. J. Chamkha, T. Grosan, and I. Pop, "Fully developed free convection of a micro polar fluid in a vertical channel," International Communications in Heat and Mass Transfer, vol. 29, pp. 11191127, 2002.

[10] H. Saleh and I. Hashim, "Simulation of micropolar fluid flow in a vertical channel using homotopy-perturbation method," in Proceedings of the Applied Computing Conference, pp. 1-4, Istanbul, Turkey, 2008.

[11] Y. M. Aiyesimi and G. T. Okedao, "MHD flow of a third grade fluid with heat transfer down an inclined plane," Mathematical Theory and Modeling, vol. 2, no. 9, pp. 108-109, 2012.

[12] K. Nrgis and T. Mahmood, "The influence of slip condition on the thin film flow of a third order fluid," International Journal of Nonlinear Science, vol. 1, no. 13, pp. 105-116, 2012.

[13] M. I. Anwar, I. Khan, A. Hussnan, M. Z. Salleh, and S. Sharidan, "Stagnation-point flow of a nanofluid over a nonlinear stretching sheet," World Applied Sciences Journal, vol. 23, no. 8, pp. 9981006, 2013.

[14] M. Qasim, I. Khan, and S. Sharidan, "Heat transfer and mass diffusion in nanofluids with convective boundary conditions," Mathematical Problems in Engineering, vol. 2013, Article ID 254973, 7 pages, 2013.

[15] A. M. Siddiqui, R. Mahmood, and Q. K. Ghori, "Homotopy perturbation method for thin film flow of a third grade fluid down an inclined plane," Chaos, Solitons \& Fractals, vol. 35, no. 1, pp. 140-147, 2008.
[16] S. J. Liao, Beyond Perturbation: Introduction to Homotopy Analysis Method, Chapman \& Hall, Boca Raton, Fla, USA, 2003.

[17] V. Marinca, N. Herisanu, and I. Nemes, "Optimal homotopy asymptotic method with application to thin film flow," Central European Journal of Physics, vol. 6, no. 3, pp. 648-653, 2008.

[18] V. Marinca and N. Herisanu, "Application of optimal Homotopy asymptotic method for solving non-linear equations arising in heat transfer," International Communications in Heat and Mass Transfer, vol. 35, pp. 710-715, 2008.

[19] V. Marinca, N. Herişanu, C. Bota, and B. Marinca, "An optimal homotopy asymptotic method applied to the steady flow of a fourth-grade fluid past a porous plate," Applied Mathematics Letters, vol. 22, no. 2, pp. 245-251, 2009.

[20] A. A. Juneidi, D. D. Gangi, and M. Babaelahi, "Micropolar flow in a porous channel with high mass transfer," International Communications in Heat and Mass Transfer, vol. 36, pp. 10821088, 2009.

[21] A. M. Siddiqui, M. Ahmed, and Q. K. Ghori, "Thin film flow of non-Newtonian fluids on a moving belt," Chaos, Solitons \& Fractals, vol. 33, no. 3, pp. 1006-1016, 2007.

[22] A. M. Siddiqui, R. Mahmood, and Q. K. Ghori, "Homotopy perturbation method for thin film flow of a fourth grade fluid down a vertical cylinder," Physics Letters A, vol. 352, pp. 404-410, 2006.

[23] T. Gul, R. A. Shah, S. Islam, and M. Arif, "MHD thin film flows of a third grade fluid on a vertical belt with slip boundary conditions," Journal of Applied Mathematics, vol. 2013, Article ID 707286, 14 pages, 2013.

[24] T. Gul, S. Islam, R. A. Shah, I. Khan, and S. Shafie, "Thin film flow in MHD third grade fluid on a vertical belt with temperature dependent viscosity," PLoS ONE, vol. 9, no. 6, Article ID e97552, 2014

[25] A. Costa and G. Macedonio, "Viscous heating in fluids with temperature-dependent viscosity: implications for magma flows," Nonlinear Processes in Geophysics, vol. 10, no. 6, pp. 545555, 2003.

[26] R. Ellahi and A. Riaz, "Analytical solutions for MHD flow in a third-grade fluid with variable viscosity", Mathematical and Computer Modelling, vol. 52, no. 9-10, pp. 1783-1793, 2010.

[27] Y. Aksoy and M. Pakdemirly, "Approximate analytical solution for flow of a third grade fluid through a parallel-plate channel filled with a porous medium," Transport in Porous Media, vol. 83, no. 2, pp. 375-395, 2010.

[28] G. Adomian, Solving Frontier Problems of Physics: The Decomposition Method, vol. 60 of Fundamental Theories of Physics, Kluwer Academic, Dordrecht, The Netherlands, 1994.

[29] G. Adomian, "A review of the decomposition method and some recent results for nonlinear equations," Mathematical and Computer Modelling, vol. 13, no. 7, pp. 17-43, 1990.

[30] A. M. Wazwaz, "Adomian decomposition method for a reliable treatment of the Bratu-type equations," Applied Mathematics and Computation, vol. 166, pp. 652-663, 2005.

[31] A. M. Wazwaz, "Adomian decomposition method for a reliable treatment of the Emden-Fowler equation," Applied Mathematics and Computation, vol. 161, pp. 543-560, 2005.

[32] M. K. Alam, M. T. Rahim, T. Haroon, S. Islam, and A. M. Siddiqui, "Solution of steady thin film flow of Johnson-Segalman fluid on a vertical moving belt for lifting and drainage problems using Adomian decomposition method," Applied Mathematics and Computation, vol. 218, no. 21, pp. 10413-10428, 2012. 


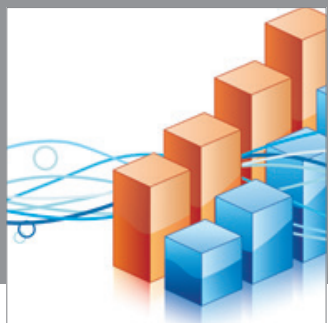

Advances in

Operations Research

mansans

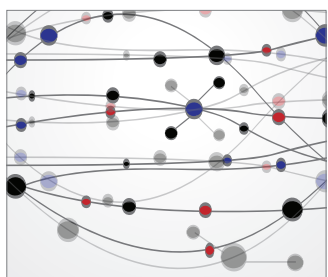

The Scientific World Journal
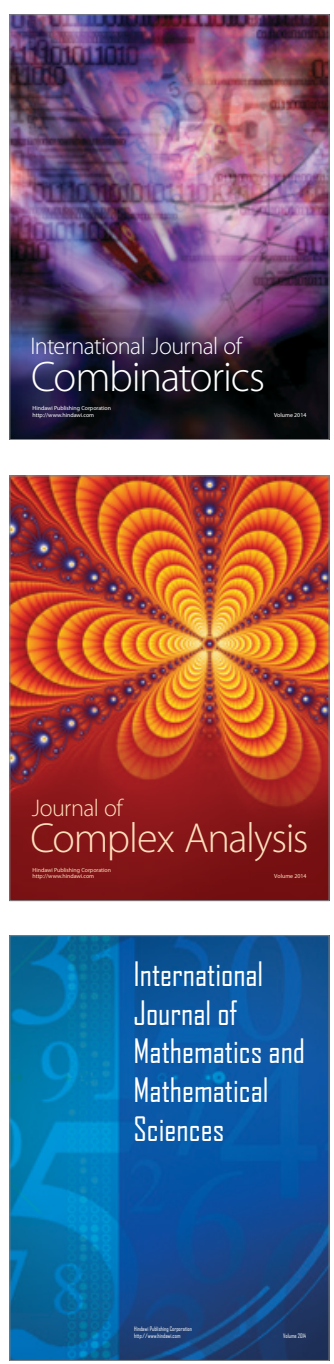
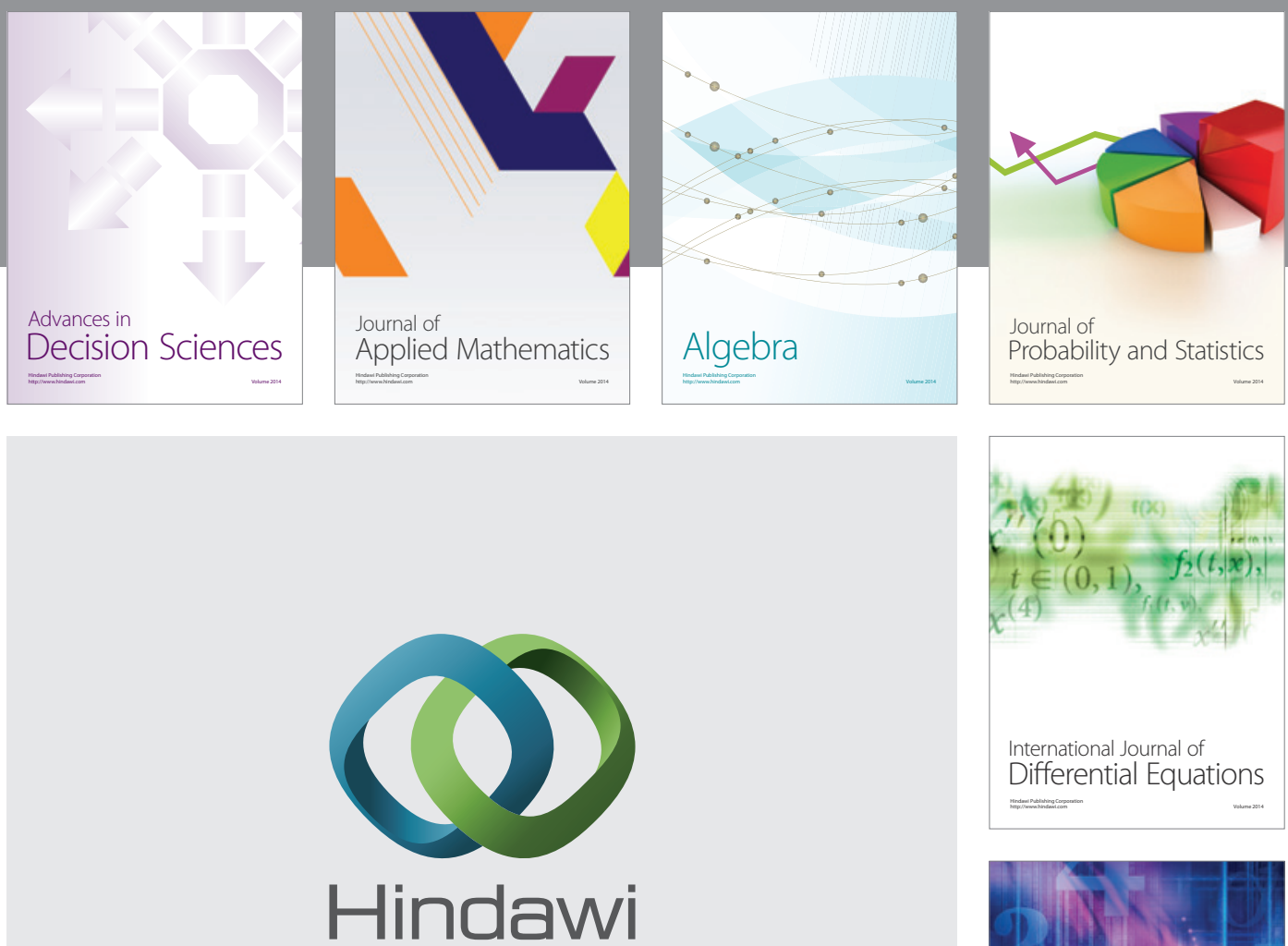

Submit your manuscripts at http://www.hindawi.com
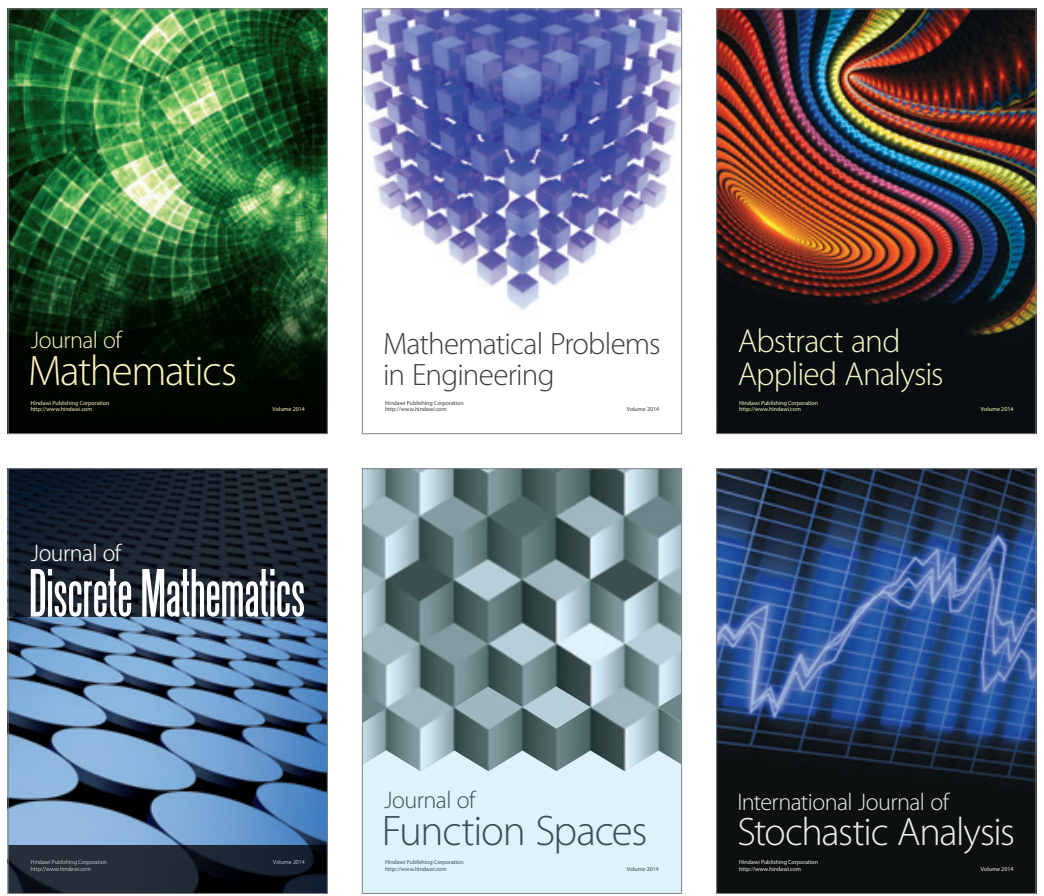

Journal of

Function Spaces

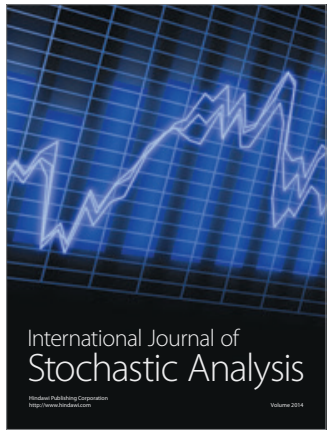

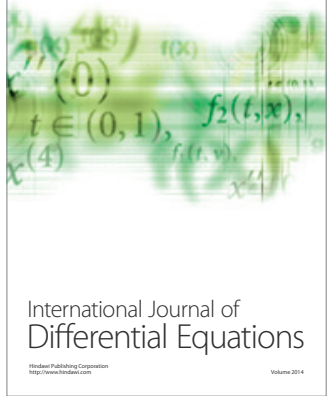
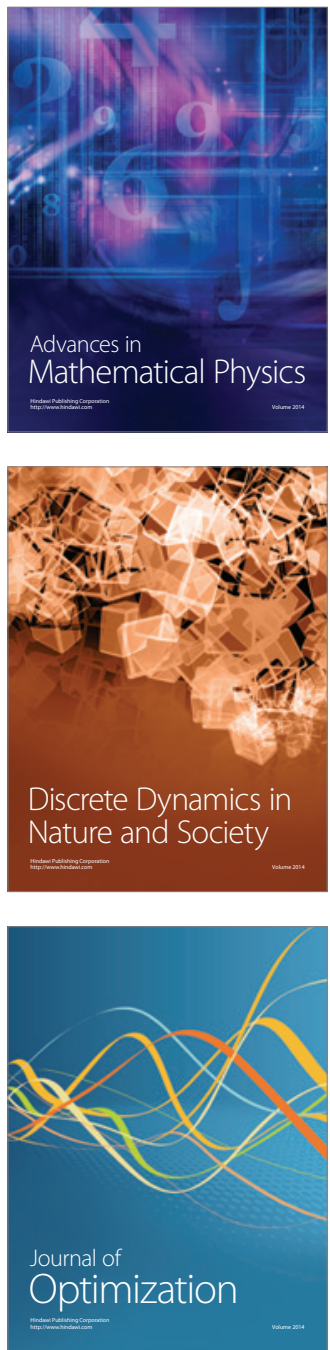